\title{
Numerical modeling of urea water based selective catalytic reduction for mitigation of NOx from transport sector
}

Article in Journal of Cleaner Production · February 2015

Impact Factor: 3.84 · DOI: 10.1016/j.jclepro.2014.06.042

CITATIONS

3

4 authors, including:

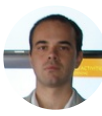

Jakov Baleta

University of Zagreb

4 PUBLICATIONS 7 CITATIONS

SEE PROFILE
Neven Duic

University of Zagreb

409 PUBLICATIONS 1,643 CITATIONS

SEE PROFILE 


\title{
Numerical modeling of urea water based selective catalytic reduction for mitigation of $\mathrm{NO}_{x}$ from transport sector
}

\author{
Jakov Baleta ${ }^{\text {a, }}$, Milan Vujanović ${ }^{\text {, }}$, Klaus Pachler ${ }^{\mathrm{b}}$, Neven Duić ${ }^{\mathrm{a}}$ \\ ${ }^{a}$ Department of Mechanical Engineering, Faculty of Mechanical Engineering and Naval Architecture, University of Zagreb, Ivana Lučića 5, \\ 10002 Zagreb, Croatia \\ ${ }^{\mathrm{b}}$ Advanced Simulation Technologies, AVL List GmbH, Alte-Poststraße 152, A-8020 Graz, Austria
}

\section{A R T I C L E I N F O}

\section{Article history:}

Received 27 December 2013

Received in revised form

12 June 2014

Accepted 13 June 2014

Available online 23 June 2014

\section{Keywords:}

Exhaust gas aftertreatment

Selective catalytic reduction

Wall film

Urea water solution

$\mathrm{NO}_{x}$ reduction

Surface tension

\begin{abstract}
A B S T R A C T
Various environmental regulations put ever stringent requirements on the automotive industry as a part of solution to the problem of global warming and climate change. In Europe, the upcoming Euro 6 standard that will come into force on September 1, 2014 demands reduction in $\mathrm{NO}_{x}$ emissions from cars and vehicles intended for transport by more than $50 \%$ compared to the current standard. The urea-watersolution (UWS) based selective catalytic reduction (SCR) is currently the most promising method for fulfilling these requirements. In principle, the UWS spray is injected into a hot exhaust gas stream preceding the SCR catalyst and ammonia is generated through series of chemical reactions. Then, the generated ammonia acts in various $\mathrm{deNO}_{x}$ reactions as a reductant.

This paper investigates application of numerical modeling in the area of environmentally friendly technology of mobile SCR as a green engineering measure to reduce pollution in the road transport sector. Within this work the mathematical model of surface tension has been developed and compared to analytical expression for isothermal droplet spreading. Furthermore, this model was incorporated into the wall film module of the commercial computational fluid dynamics code FIRE for description of ureawater-solution injection into hot exhaust gases of diesel engine and compared to experimental data. Results of the conducted numerical study support the feasibility of commercial application of the presented model.
\end{abstract}

(c) 2014 Elsevier Ltd. All rights reserved.

\section{Introduction}

Transport is one of the most challenging sectors when addressing energy security and climate changes (Liu et al., 2013). Preferred option for accomplishing goals of cleaner production is through improved governmental policies (Klemeš et al., 2012), one of them being European emission standards. Strict requirements of the upcoming Euro 6 (Regulation (EC) No 715/2007) standard can only be met by a combination of new exhaust gas aftertreatment and advanced engine technologies. For the commercial diesel engines, this means the use of common rail fuel injection systems with pressures of up to 2500 bar, charging pressures of 4 bar and exhaust gas recirculation up to $30 \%$ at full load (Kröcher et al., 2008). Further reduction of $\mathrm{NO}_{x}$ emissions below emission limits can be achieved by a suitable exhaust gas aftertreatment system. The most promising technology for reduction of $\mathrm{NO}_{x}$ is selective

\footnotetext{
* Corresponding author. Tel.: +38516168 494; fax: +38516156940.

E-mail addresses: jakov.baleta@fsb.hr (J. Baleta), milan.vujanovic@fsb.hr (M. Vujanović), klaus.pachler@avl.com (K. Pachler), neven.duic@fsb.hr (N. Duić).
}

catalytic reduction in the exhaust gas system using ammonia produced from precursor substances such as urea. Due to combustion with the oxygen excess in diesel engines, $\mathrm{O}_{2}$ is present in the exhaust gas in higher concentration, which makes a simple reduction of $\mathrm{NO}_{x}$ very difficult. Generally, all the applicable reducing agents prefer to react with oxygen prior to the conversion of the less reactive NO, because reaction with NO has higher activation energy. Application of a catalyst lowers that energy, so that the reaction proceeds selectively towards the nitrogen, without the reductant being oxidized. Hence the generally known name - selective catalytic reduction (SCR).

Spatially uniform distribution of the reducing agent that precedes the SCR catalyst is a crucial factor for the conversion of $\mathrm{NO}_{x}$. The uniformity of distribution and the degree of processing of the reducing agent upstream of the SCR catalyst can be, besides the evaporation and decomposition, influenced also by the spray/wall interaction.

Usage of CFD simulations to investigate and improve thermochemical processes is becoming increasingly important (Klemeš et al., 2010). Well established mathematical models of all relevant 
physical phenomena regarding the SCR, which are implemented in the commercial CFD codes, form the basis for the design of modern selective catalytic reduction systems, including dozing apparatus (Kim et al., 2004; Nguyen et al., 2010; van Helden et al., 2004). In the upcoming sections the possibility of numerical modeling of urea-water-solution injection into hot exhaust gases using the CFD code FIRE (FIRE, 2013) is investigated.

\section{Mathematical model}

In this study, as in the most engineering applications today, the Eulerian-Lagrangian method for solving the multiphase flow phenomena is used. In this approach, the spray droplets are represented by finite numbers of droplet groups called parcels. It is assumed that all the droplets within one parcel are similar in size and have the same physical properties. The motion and the transport of the parcels are tracked through the flow field using a Lagrangian formulation, while the gas phase is described by solving conservation equations using an Eulerian formulation. The coupling between the liquid and the gaseous phase is taken into account by introducing appropriate source terms for interfacial mass, momentum, and energy exchange (Mikulčić et al., 2013).

\subsection{Continuous phase}

The constitutive equations of continuum mechanics are based on the conservation laws for mass, momentum and energy. The general form of the time averaged conservation equation for any dependent variable $\varphi$, of the continuous phase in the differential form is:

$\frac{\partial}{\partial t} \rho \varphi+\frac{\partial}{\partial x_{j}}\left(\rho \varphi \mu_{j}\right)=\frac{\partial}{\partial x_{j}}\left(\Gamma_{\varphi} \frac{\partial \varphi}{\partial x_{j}}\right)+S_{\varphi}$,

where $\rho$ is the density, $u_{j}$ Cartesian velocity, $\Gamma_{\varphi}$ diffusion coefficient, and $S_{\varphi}$ is the source term of the dependent variable $\varphi$. In Eq. (1) the first term is an unsteady term, the second term is convection, the third term is diffusion and the last term is source or sink. The source term $S_{\varphi}$ is used for the coupling of the liquid and the gaseous phases (Mikulčić et al., 2012a).

\subsection{Urea water solution injection}

Urea-water solution (UWS) is the most commonly used ammonia precursor for mobile SCR applications since it represents no danger for environment in the case of a traffic accident. AdBlue is a commercial name for an aqueous urea solution blended with $32.5 \%$ high purity urea and $67.5 \%$ deionized water.

Once AdBlue spray is injected into the hot exhaust gas stream before the SCR catalyst, water evaporates from the UWS. Afterwards, ammonia is generated through thermal decomposition of urea and hydrolysis of isocyanic acid:

$\left(\mathrm{NH}_{2}\right)_{2} \mathrm{CO} \rightarrow \mathrm{NH}_{3}+\mathrm{HNCO}$

Hydrolysis of isocyanic acid:

$\mathrm{HNCO}+\mathrm{H}_{2} \mathrm{O} \rightarrow \mathrm{NH}_{3}+\mathrm{CO}_{2}$

Generated ammonia takes part in various $\operatorname{deNO}_{x}$ reactions as a reductant (Fang and DaCosta, 2003):

$4 \mathrm{NH}_{3}+4 \mathrm{NO}+\mathrm{O}_{2} \rightarrow 4 \mathrm{~N}_{2}+6 \mathrm{H}_{2} \mathrm{O}$ (standard SCR)

$4 \mathrm{NH}_{3}+2 \mathrm{NO}_{2}+2 \mathrm{NO} \rightarrow 4 \mathrm{~N}_{2}+6 \mathrm{H}_{2} \mathrm{O}$ (fast SCR)

$\mathrm{NO}_{x}$ in diesel exhaust is usually composed of $>90 \%$ of $\mathrm{NO}$ and only $5-10 \%$ of $\mathrm{NO}_{2}$. Therefore, the main reaction of SCR with ammonia is a reaction (4). The reaction with equimolar amounts of $\mathrm{NO}$ and $\mathrm{NO}_{2}(5)$ is much faster than the main reaction and therefore is called the fast SCR reaction. The $\mathrm{NO}_{2}$ needed for the fast SCR reaction could be produced from engine-emitted NO in the preoxidation catalyst. Under ideal spraying conditions for the urea water solution, engine test results have shown a stoichiometric ratio of 2.2-2.9 mol of NO per $1 \mathrm{~mol}$ of urea consumption (Fang and DaCosta, 2003). This is equal to a weight ratio $0.67-0.9 \mathrm{~g}$ of urea required to reduce $1 \mathrm{~g}$ of $\mathrm{NO}$ in the exhaust.

In order to include all relevant phenomena appearing during the injection of urea-water solution into a confined space of mobile SCR systems, a suitable mathematical description of the following processes is needed (Birkhold et al., 2006):

- Momentum interaction between the gas phase and droplets;

- Evaporation and thermolysis of droplets;

- Heat transfer between the wall and droplets;

- Spray/wall interaction;

- Two-component wall film interaction with the gas phase and the exhaust tube;

- Secondary break-up of the spray.

This section presents the basics of some mathematical models implemented in the commercial CFD code FIRE used for conducting of numerical simulations.

\subsubsection{Evaporation and thermolysis of UWS droplets}

Despite numerous experimental studies (Kontin et al., 2010; Musa et al., 2006; Wang et al., 2009), theoretical understanding of evaporation and decomposition of UWS droplets is still far from satisfactory. Theoretical study conducted by Birkhold et al. (2007) was implemented in FIRE and represents the trade-off between accuracy of results and computational demands. This approach assumes a two-stage process - pure water evaporation until the droplet is composed of urea only, and subsequent thermolysis. It is also assumed that the droplets remain spherical throughout the evaporation and decomposition processes, and there is no urea crystallization.

2.2.1.1. Water evaporation. In order to evaluate the influence of dissolved urea on the evaporation of water, Rapid Mixing Model is employed. Within this model, infinitely high transport coefficients are assumed for the liquid phase, resulting in spatially uniform temperature, concentration and fluid properties in the droplet. However, these parameters will change in time (Abramzon and Sirignano, 1989). The variation in droplet's urea concentration can be evaluated by:

$\frac{\mathrm{d} Y_{u}}{\mathrm{~d} t}=-\frac{\dot{m}_{\mathrm{vap}}}{m_{d}} Y_{u}$

where $Y_{u}$ is urea concentration, $m_{d}$ is a droplet mass and $\dot{m}_{\mathrm{vap}}$ is a vapor mass flow. Evaporation rates are calculated using the Abramzon-Sirignano model, which represents the extension of the classical droplet vaporization model (Dukowicz, 1979) and includes important effects such as variable physical properties, variable Lewis number in the gas phase and the influence of the Stefan flow on the heat and mass transfer. The model has low computational demands per droplet and therefore is suitable for the spray calculations that simultaneously trace many individual droplets.

2.2.1.2. Urea thermolysis. Urea melts at $406 \mathrm{~K}$, at which point the thermal decomposition of urea into ammonia and isocyanic acid starts. 
Arrhenius-type expression describes chemical kinetics of the reaction:

$\frac{\mathrm{d} m_{u}}{\mathrm{~d} t}=-A_{f} S \exp \left(-E_{a} / R T_{d}\right)$

where $m_{u}$ is urea mass, $S$ is droplet surface area, $A_{f}$ is the frequency factor $\left[\mathrm{kg} /\left(\mathrm{sm}^{2}\right)\right], T_{d}$ is the droplet temperature, $R$ is the universal gas constant and $E_{a}$ is the activation energy. Experimental data from Yim et al. (2004) were used for a default parameter fit. The wall film approach for evaporation of UWS is similar, except for the thermolysis, which occurs when the mass fraction of water is less than $5 \%$.

\subsubsection{Spray/wall interaction model}

According to dimensionless analysis carried out by Kuhnke (2004), there are four different regimes of spray-wall interaction depending on the dimensionless wall temperature and the dimensionless droplet velocity, as presented in Fig. 1. Dimensionless temperature is defined as follows:

$T^{*}=\frac{T_{W}}{T_{S}}$

where $T_{W}$ is the wall temperature and $T_{S}$ is the droplet saturation temperature.

Dimensionless droplet velocity is defined as:

$K=\frac{\left(\rho_{d} D_{d}\right)^{3 / 4} u_{d, \perp}^{5 / 4}}{\sigma_{d}^{1 / 2} \mu_{d}^{1 / 4}}$

where $\rho_{d}$ is the droplet density, $u_{d, \perp}$ is the wall normal component of the droplet velocity, $\sigma_{d}$ is the surface tension on the droplet-gas interface, $D_{d}$ is the droplet diameter and $\mu_{d}$ is the dynamic viscosity of the droplet.

\subsubsection{Wall film modeling}

Wall film model is implemented as a 2D finite volume method on the airflow wall boundaries. The film thickness equation is the basic governing equation for the wall film flow. It represents a slightly modified formulation of the continuity equation where, instead of mass, the wall film thickness is a conserved property. The Cartesian formulation of the film thickness equation is:

$\frac{\partial \delta}{\partial t}+\frac{\partial \delta u_{1}}{\partial x_{1}}+\frac{\partial \delta u_{2}}{\partial x_{2}}=\frac{1}{\rho A}\left(S_{m D}-S_{m V}\right)$

where $\delta$ is the film thickness, $\rho$ is the film density, $u_{1}$ and $u_{2}$ are film velocity components, $S_{m D}$ and $S_{m V}$ are source/sink terms and $A$ is

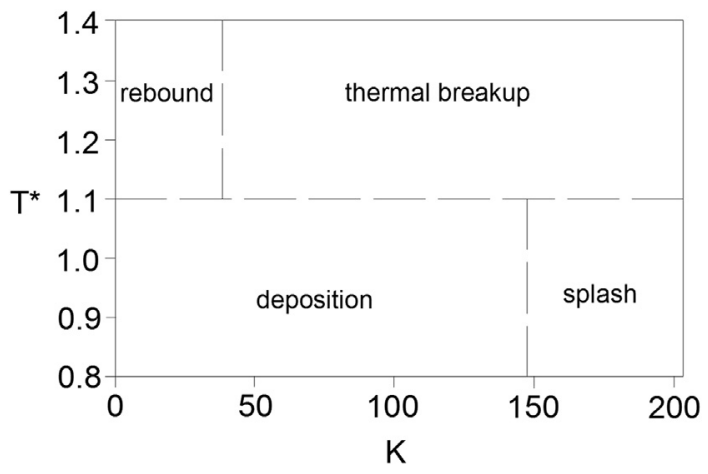

Fig. 1. Diagram of spray/wall interaction - Kuhnke (2004). the surface area of the film. If we assume that the source terms are provided, Equation (10) can be solved explicitly if the velocity components are known.

The current wall film model in the commercial CFD code FIRE contains mathematical description of physical phenomena in the form of three conservation laws: conservation of mass, momentum and energy. However, the surface tension effects, which are of great importance at the late film spreading stages when the inertial forces are negligible (Horvat, 2007) as well as when shear-driven film comes at a sharp expanding corner (Friedrich et al., 2008), are not taken into account.

The film surface tension effects that are present at the boundary edges of the liquid phase play a crucial role in slowing down the film progression. These effects are not currently accounted for, and approximation of constant film thickness over the control volume does not allow reconstructing the characteristics of the interface. That way, the scattering of liquid film causes high numerical diffusion, which does not correspond to physical reality. The threshold value of the minimal film thickness can be set by the user, and only the cells where the film is thicker are considered active. Such an approach is not suitable. Therefore, the objective of this work is also improvement of the current model by incorporating appropriate mathematical description of surface tension effects.

The continuum surface force (CSF) method of Brackbill has been employed extensively over the last 13 years to model the surface tension in various fixed (Eulerian) mesh formulations for interfacial flows, in particular in the volume-of-fluid (VOF), the level-set (LS) and the front tracking (FT) interface representation techniques (Francois et al., 2006). The main drawback of mentioned approaches is that they are unsuitable for finite area Eulerian approach because of high computational demands. Those are usually used on small scale interfaces such as impinging droplet or few droplet collisions. Another approach to describe surface tension was made by Bai (1996), who developed the solution procedure where capillary forces are taken into account through a capillary pressure term. It is suitable to incorporate this pressure term into the momentum equation of wall film. The details of the procedure are given as follows.

The film momentum equation describes dynamics of liquid film interaction with its environment - wall, air stream above the film, impinging droplets, etc. Equation (11) gives mathematical formulation of the wall film momentum conservation law:

$\frac{\mathrm{d} M_{i}}{\mathrm{~d} t}=\oint_{L} \rho u_{i}\left(u_{i}-V_{j}\right) \widehat{n}_{i} \mathrm{~d} L=\int_{L} p \delta \widehat{n}_{i} \mathrm{~d} L+m g_{i}+\Gamma_{i}+S_{M}$

where $M_{i}$ is film momentum, $\rho$ is the film density, $u_{i}$ is film velocity, $V_{j}$ is wall velocity, $\widehat{n}_{i}$ is normal to the face cell facing outwards, $d L$ is differential length of the face cell boundary, $\delta$ is the film thickness, $p$ is film pressure, $m$ is film mass, $g_{i}$ is the component of gravity vector, $\Gamma_{i}$ is the term that takes into account all shear stresses and $S_{m}$ presents various source and sink terms such as film entrainment, spray droplets impingement and film evaporation.

Inclusion of surface tension effects into the pressure term of momentum equation was made by calculating the capillary pressure. This force drives the surface towards a minimal energy state characterized by a configuration of minimum surface area and is represented by the combined action of liquid surface tension $\sigma$ and film surface curvature $C$ (Horvat, 2007):

$p_{\sigma}=-\sigma C$

As shown in O'Brien and Schwartz (2006) and Schwartz and Weidner (1995), the mean curvature of the free surface can be approximated using the following expression: 
$C \approx\left(\frac{1}{R_{1}}+\frac{1}{R_{2}}\right)+\left(\frac{\delta}{R_{1}^{2}}+\frac{\delta}{R_{2}^{2}}\right)+\nabla \bullet \nabla \delta$

On quality computational meshes the surface area patches are so small that the first two terms of Equation (13) could be neglected. Thus, the film surface curvature could be approximated with Laplacian of film thickness whose numerical form is:

$\Delta \delta=\nabla \bullet \nabla \delta=\frac{1}{S} \sum_{i=1}^{n_{\text {edges }}} n_{i} \nabla \delta \cdot L_{i}=\frac{1}{S} \sum_{i=1}^{n_{\text {edges }}} n_{i} \frac{\delta_{B}-\delta_{A}}{\overline{A B}} \cdot L_{i}$

where $\nabla$ is del operator, $\delta$ is the film thickness, $S$ is surface patch area, $L_{i}$ is the length of the neighboring edge, $n_{i}$ is unit normal on common edge facing outwards and $\overline{A B}$ is length between cell centers $A$ and B. Equation (14) was incorporated into the pressure term of momentum equation of the existing numerical framework.

\section{Experimental setup}

For the investigation, a six-hole injector (200 $\mu$ m hole diameter) made by Emitec, type EM-A1.3, was used. The cycle time was $100 \mathrm{~ms}$. In order to achieve the desired flow rate of $2.5 \mathrm{~kg} / \mathrm{h}$, the opening and closing times of the injector needle were changed with a frequency generator Rigol DG1022, which was connected to the injector via an amplifier.

\subsection{Spray calibration}

Experiments were conducted using a water at $25^{\circ} \mathrm{C}$. Water was injected at a relative pressure of 8 bar into a quiescent air at $20^{\circ} \mathrm{C}$ vertically from above the rectangular test chamber where injector was mounted. Visualization of spray behavior inside the test chamber was performed using the AVL VisioScope which is a digital, triggerable video system especially designed for the IC engine research. The images delivered by a digital camera are transmitted straight to the PC as digital data and therefore with no loss of quality.

The so called spray pattern represents the spatial distribution of a liquid mass on a plain perpendicular to the spray axis, measured at a fixed distance from the nozzle. The device for measuring the spray pattern is conveniently called a patternator. In our case it consisted of 61 tubes $(d=5.25 \mathrm{~mm})$ arranged in a circular form. The measuring procedure consists of positioning the patternator at different distances from the nozzle, perpendicular to the spray axis. The injected liquid was captured by the patternator tubes. By analyzing the amount of liquid collected in each tube was possible to deduce the spray mass distribution at given distances.

Finally, the Spraytec instrument was used to measure the size of spray particles using the laser diffraction technique.

\subsection{Test rig}

A test rig with a rectangular cross-section made of transparent and heat-resistant borosilicate glass was used for the analysis of wall film and air composition. Its dimensions were $970 \times 120 \times 45 \mathrm{~mm}$ and it was available for optical measuring methods. Experiments were conducted using pure air. For the introduction of AdBlue into the test section the same injector that was described in Section 3, was used with identical operating conditions. The injector was located $40 \mathrm{~mm}$ after the inlet and was delivering the liquid perpendicular to the inlet air stream. Concentrations of ammonia and isocyanic acid formed during the urea thermolysis were determined at the outlet of the test chamber using Fourier transform infrared spectroscopy (FTIR). Sampling of air was conducted at twelve points that were vertically distributed across the channel cross-section, at 13, 18, 23 and $30 \mathrm{~mm}$.

\section{Results and discussion}

This section presents results of numerical simulations, which investigated the spray interaction with the hot air stream and wall. As the modeling of primary breakup is still insufficiently understood, the first step was spray calibration. The obtained spray parameters, together with the newly developed surface tension model, served as an input for the main simulation of urea thermal decomposition in rectangular flow channel geometry.

\subsection{Spray calibration}

Numerical simulations of the spray processes were based on the Lagrangian multiphase model implemented in the CFD code FIRE, which takes into account full two-way coupling between the gas and liquid phase.

The simulation domain had a rectangular shape. A threedimensional $35 \times 35 \times 60 \mathrm{~mm}$ computational mesh with 73500 orthogonal hexahedron cells was used. The wall boundary conditions were defined at the top and bottom of the domain, whilst a static pressure outlet was imposed at the sides. In the FIRE code, a nozzle is defined as a point in a domain and is described by a set of parameters given in the so called nozzle file. The domain pressure and temperature were initialized according to the experimental data.

The pressure velocity coupling of momentum and continuity equation was obtained using the SIMPLE/PISO algorithm. The central difference discretization scheme was used for the convective term in the continuity equation with a blending factor of 1 , whilst a MINMOD Relaxed with a blending factor of 0.5 was used for the convective terms in the momentum equations. The most favored method for modeling the turbulent flows in industrial applications is the Reynolds-averaged Navier-Stokes equations (RANS) with an appropriate turbulence model. Many turbulent models employ the concept of a turbulent viscosity or a turbulent diffusivity to approximate the turbulent Reynolds stresses and the turbulent heat fluxes (Mikulčić et al., 2012b). In this work the turbulence was modeled by the advanced k-zeta-f model (Hanjalić et al., 2004). The spray calibration procedure consisted of the steps described below.

\subsubsection{Spray penetration}

Analysis of the spray penetration inside the test chamber provided data for the simulations carried out in order to determine the start velocity of the spray. In the FIRE the start velocity can be specified by a certain function, table or it can be set as constant. Relatively low injection pressure of 8 bar enables the usage of constant start velocity. Experimental data of spray penetration as a function of time were extracted from the Visioscope measurements.

Fig. 2 shows comparison between the measured and the calculated results in the case of AdBlue as an injected liquid. It demonstrates that the spray penetration curve has almost linear profile. There are only indications of expected saturation at the end of the curve. This is a consequence of high velocities, big droplets and relatively small dimensions of the test chamber, so that the aerodynamic forces due to relative velocity between the droplets and air cannot significantly slow down the spray droplets and thus yield a more familiar saturated spray penetration curve.

Despite the fact that the experiments were carried out with water, there was no noticeable difference between the penetration of AdBlue and the water spray. In the case of water, the best 


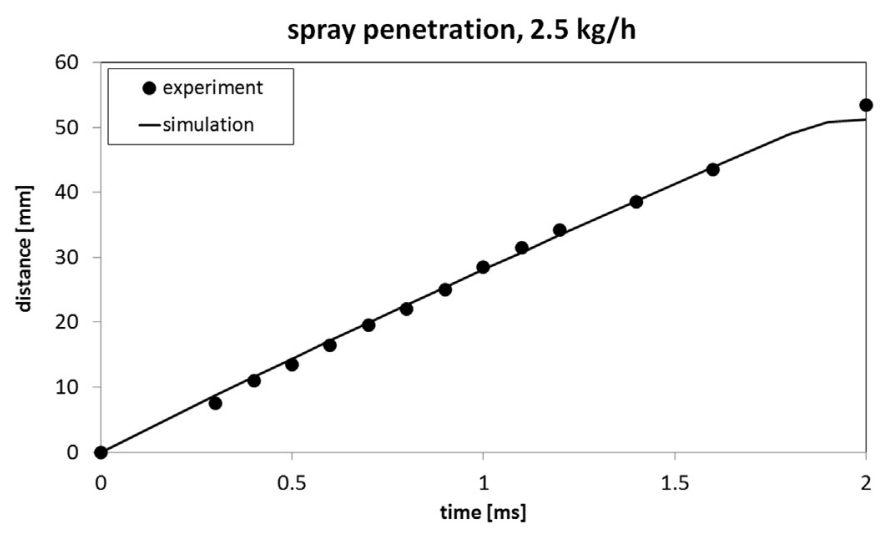

Fig. 2. Spray penetration - comparison between simulation and experiment.

agreement with the experimental results was achieved by setting the start velocity at $29 \mathrm{~m} / \mathrm{s}$ and this value had to be corrected to $29.8 \mathrm{~m} / \mathrm{s}$ for AdBlue.

\subsubsection{Spray pattern}

The injection direction of the nozzle orifices and the angle of the spray plumes depicted in the Fig. 3 were varied in numerical simulation in order to match the spray patterns obtained by the patternator measurements. The simulation set-up was slightly different than that of the spray penetration. A known mass from the patternator measurements was injected in one cycle over the $1 \mathrm{~s}$ time, because the mass flow does not affect the spray pattern. In the Fig. 3 legend, the first angle indicates orifice inclination, while the second one indicates the angle of spray plumes. The value of $8^{\circ}$ for both angles yields a very good agreement with the measured data, as can be seen in the Fig. 4. The last check of the selected values was performed on the mesh that enables simulation of the spray pattern from the nozzle at a $50 \mathrm{~mm}$ distance. Agreement with the experiment, as shown on the right diagram in Fig. 4, is satisfactory, although not as good as at the $30 \mathrm{~mm}$ distance. The area occupied by the spray is larger and the mass is more evenly distributed, as expected when increasing the nozzle distance.

With respect to all of the above, the final values of the spray angles were $8^{\circ}$ for both the injection direction of the nozzle orifices and the angle of the spray plumes.

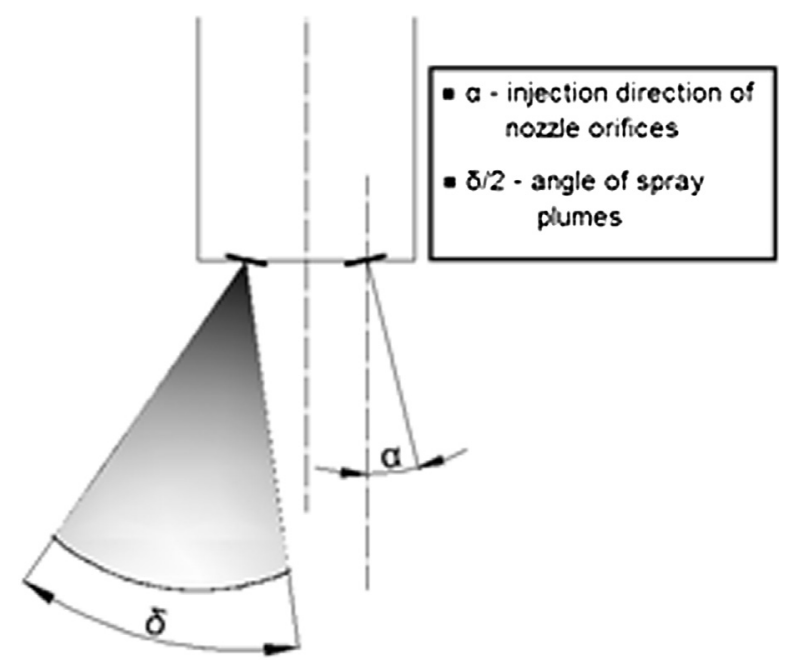

Fig. 3. Schematic representation of spray angles.

\subsubsection{Particle size distribution}

The final step of the spray calibration was determination of the initial particle size distribution (PSD). This is the most important initial condition since the primary break-up mechanisms implemented in the FIRE cannot be used for low injection pressures that prevail in the SCR applications (Gapin et al., 2010).

The initial particle size distribution was specified using experimental measurements at the $30 \mathrm{~mm}$ distance from the nozzle. They were slightly modified, keeping the integral of surface under the curve equal to 1 . The accuracy of the modified distribution for initializing the simulation was verified by comparing the extracted PSD curve for a $30 \mathrm{~mm}$ distance from the nozzle with the same experimental data that were the basis for the modified distribution. In order to obtain a reliable average for comparison with the experiment, two injection cycles were simulated. Fig. 5 shows verification of the chosen initial PSD curve. For a visual clarity, simulation results are shown with markers, contrary to the convention.

The chosen input curve is confirmed by a good agreement between the simulated and measured PSD at a $30 \mathrm{~mm}$ distance. There are some deviations at the beginning of the curve, most likely attributable to the error in experiment due to the vertical beginning of the experimental curve, which is nonphysical. The average Weber number was below 12. Therefore, according to Birkhold et al (2006), it appears reasonable to assume the absence of any secondary atomization process.

\subsection{Validation of implemented surface tension model}

In order to test the numerical scheme and to check if the capillary pressure effects can be predicted properly, there is a need for a simple case, where only the capillary force effects are relevant. Thus, the spreading of an isothermal droplet on a solid surface is simulated. The droplet is driven with a Laplace (capillary) pressure as dominant force and other forces being absent or negligible. Similar tests were obtained by Diez et al. (1994). He proposed an analytical solution using lubrication theory, which neglects convective terms in the momentum equation, and confirmed it experimentally. The problem can be observed as a two-dimensional because of axial symmetry. Diez et al. (1994) showed that the normalized film thickness $h / h_{0}$ can be expressed as a single function of the scaled radial position $r / r_{f}$, irrespective of the time level.

The simulation domain with the relevant boundary conditions is shown in Fig. 6. A three- dimensional $5 \times 5 \times 0.1 \mathrm{~mm}$ computational mesh with 20000 orthogonal hexahedron cells was used for the simulation. The wall boundary condition was defined at the bottom of the domain, whilst a static pressure outlet was imposed at all other sides. The domain pressure was 1 bar and temperature was equal to the droplet temperature. The pressure velocity coupling of momentum and continuity equation was obtained using the SIMPLE/PISO algorithm. The central difference discretization scheme was used for the convective term in the continuity equation with a blending factor of 1 , whilst a MINMOD Relaxed with a blending factor of 0.5 was used for the convective terms in the momentum equations. Turbulence model was deactivated, since a quiescent air is necessary for comparison with analytical expression. Energy equation was also deactivated, so that the only relevant force is capillary pressure, which tends to spread a given droplet shape into a state of minimal surface energy.

The simulation starts from a drop, which initially takes a shape of a rotational paraboloid, with a volume of $0.12 \mathrm{~mm}^{3}$ and $0.08 \mathrm{~mm}$ thickness at the center. The spatial and time discretization increment were $0.05 \mathrm{~mm}$ and $10^{-5} \mathrm{~s}$, respectively. Simulation time was $0.5 \mathrm{~s}$, since the spreading of the droplet practically remained unchanged around and after $0.4 \mathrm{~s}$. 
nozzle distance: $30 \mathrm{~mm}$

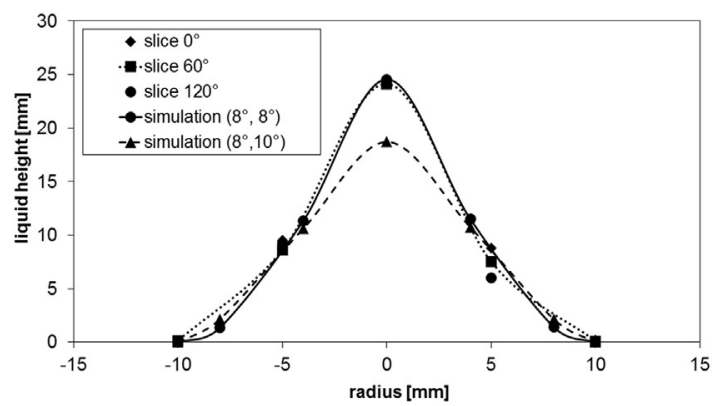

nozzle distance: $50 \mathrm{~mm}$; coarse mesh



Fig. 4. Comparison between the simulated spray pattern and the experiment.

Quantitative comparison of simulation results and nondimensional analytical droplet profile given in Fig. 7 shows that the present numerical predictions are in excellent agreement with the experimental data, indicating that the numerical modeling of the capillary pressure is reasonable in terms of trade-off between the accuracy of results and computational demands. However, the model does not include correction of the film curvature at the film front due to the wettability effects represented by the dynamic contact angle. These effects are omitted from modeling due to the relatively large spatial discretization, which prevails in most of the practical applications where the wall film phenomena are important.

\subsection{Main simulation}

The experiments carried out on the test section have supplied data for the numerical simulations, where the cases with and without the surface tension model were compared to the experimental data.

\subsubsection{Simulation settings}

The simulation domain with relevant boundary conditions is shown in Fig. 8. A three dimensional $970 \times 120 \times 45 \mathrm{~mm}$ computational mesh with 335280 hexahedron cells was used for the simulations. The mesh was refined in the vicinity of the nozzle in order to capture transient spray behavior. A boundary layer was also created towards the bottom plate as the wall film formation was expected to occur during the injection. The inlet was described with normal velocity, air temperature, turbulent kinetic energy and turbulent length scale.

\section{$2.5 \mathrm{~kg} / \mathrm{h} ; 30 \mathrm{~mm}$}



Fig. 5. Number based droplet size distribution.
The pressure velocity coupling of the momentum and continuity equations was obtained using the SIMPLE algorithm. The central difference discretization scheme was used for the convective term in the continuity equation with a blending factor of 1 , whilst a MINMOD Relaxed with the same blending factor was used for the convective terms in the momentum equations. Turbulence was modeled using the k-zeta-f model as was the case in Section 4.1.

Heat transfer through the wall was modeled using thin wall module that approximates the temperature profile of the wall with mean temperature. Heat loss towards the environment was modeled through the combined effect of convection and radiation. External heat transfer coefficient was set to $20 \mathrm{~W} /\left(\mathrm{m}^{2} \mathrm{~K}\right)$, which was a reasonable assumption for a free convection in the environmental air. External wall emissivity was taken to be 0.3 , and external air temperature was set to $293.15 \mathrm{~K}$ according to the experiment.

\subsubsection{Results}

Fig. 9 shows the wall film evolution in the case without surface tension model, i.e. default model. It can be seen that the increase of the surface covered with film gradually diminishes over time. The increase in the film covered area formed between the 3rd and 7th second is larger than the one formed between the 7th and 10th second. Furthermore, after $10 \mathrm{~s}$ the surface occupied by the wall film remains unchanged, as well as the wall film shape. It can be concluded that a quasi steady state occurred. Most of the film mass is deposited at the peripheral parts of the film due to the influence of the main flow. The deposited liquid front of semi-circular shape propagates in the direction of the main flow. Due to the effect of viscosity, it leaves a liquid trail behind. The average film thickness in those areas was between 200 and $250 \mu \mathrm{m}$.

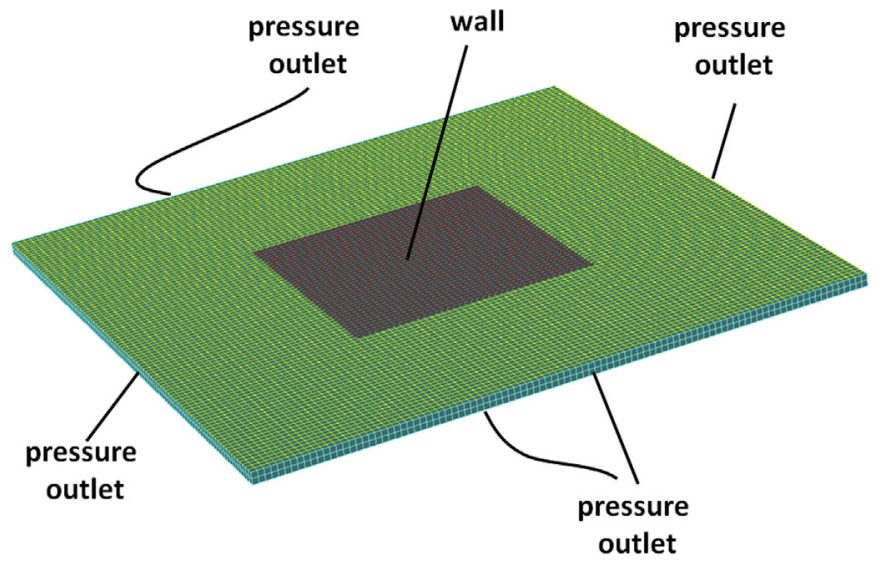

Fig. 6. Computational domain for droplet spreading case. 


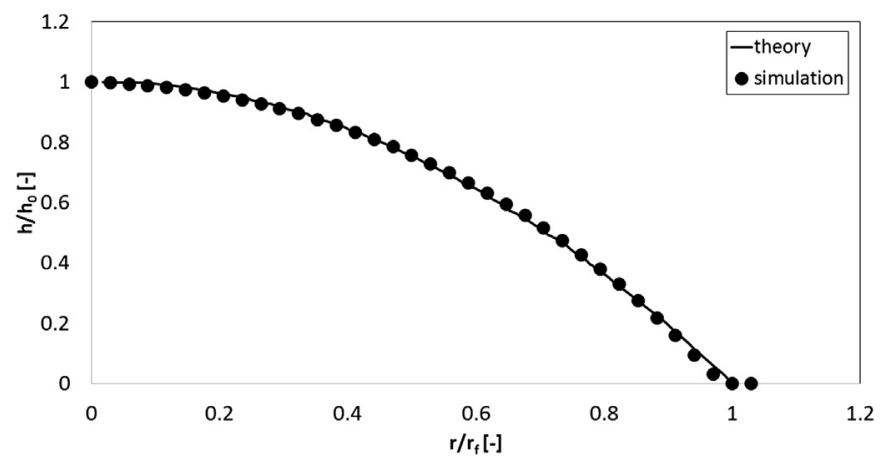

Fig. 7. Comparison of simulation with non-dimensional analytical profile.

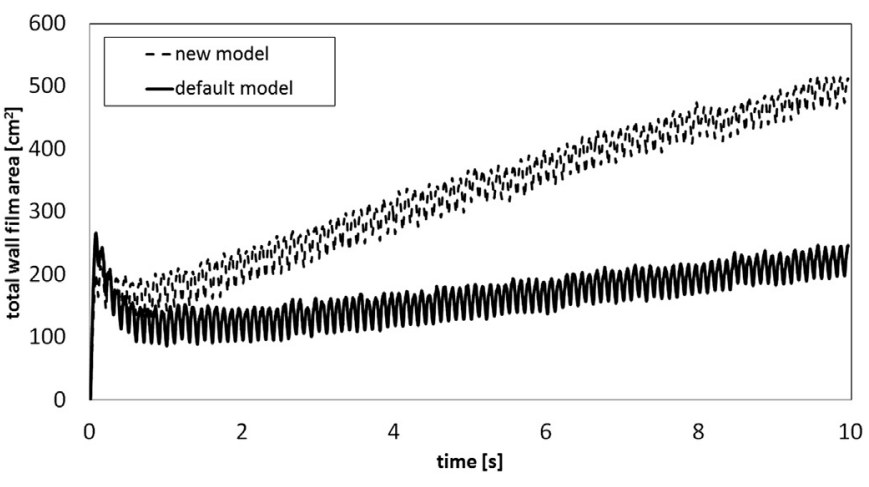

Fig. 11. Comparison of total film area.

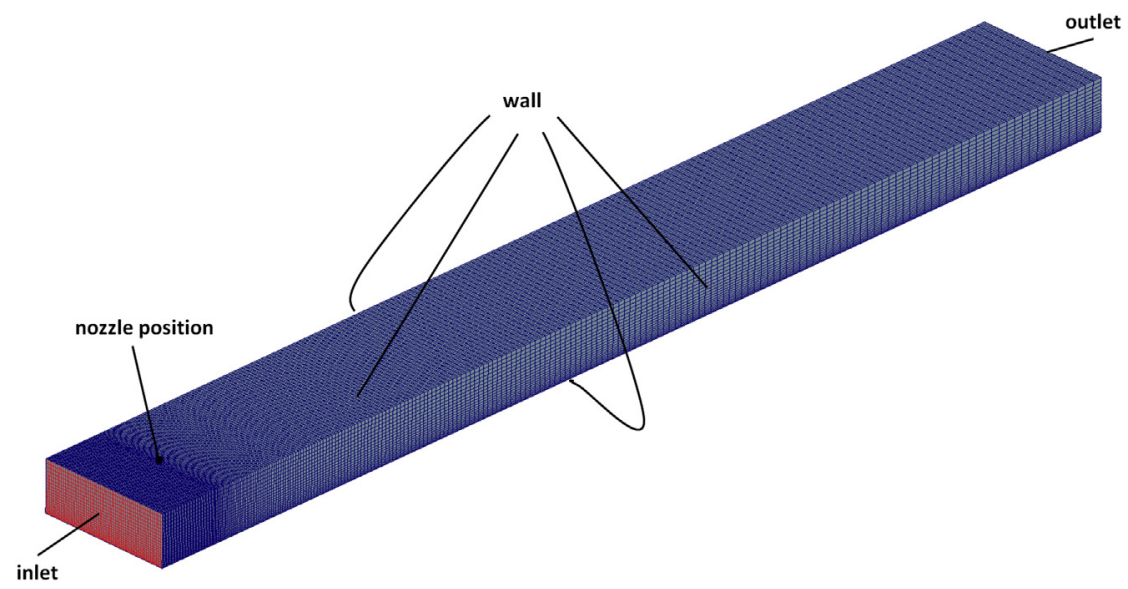

Fig. 8. Computational domain with boundary conditions.

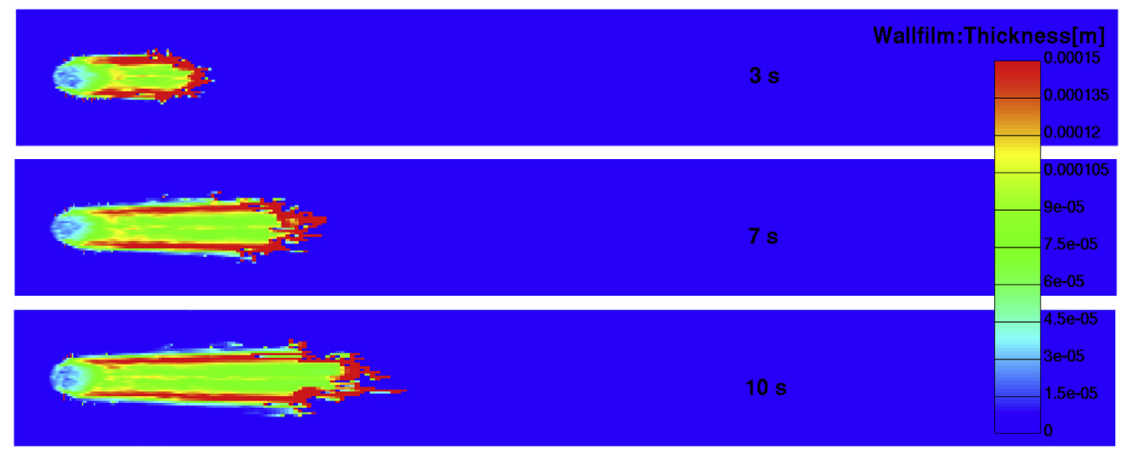

Fig. 9. Wall film development - default model.

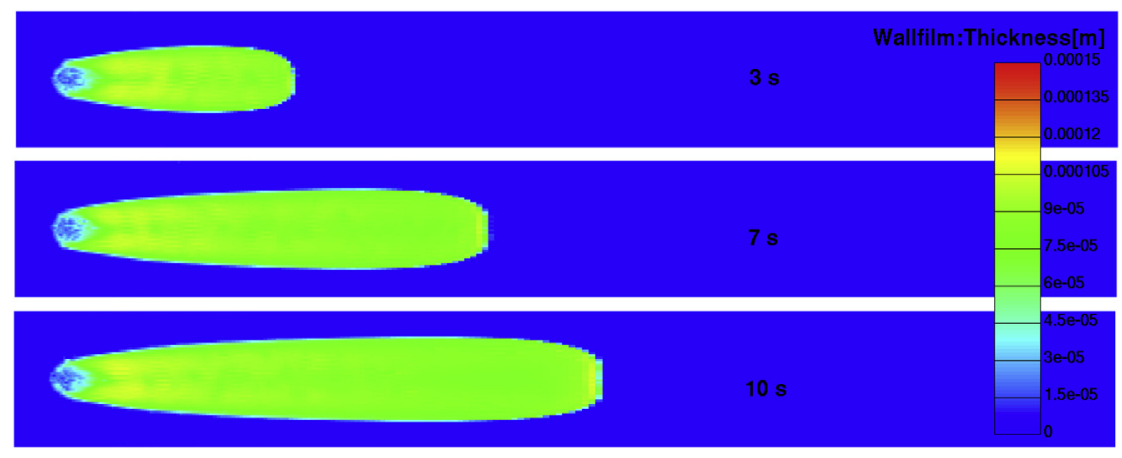

Fig. 10. Wall film development - new model. 


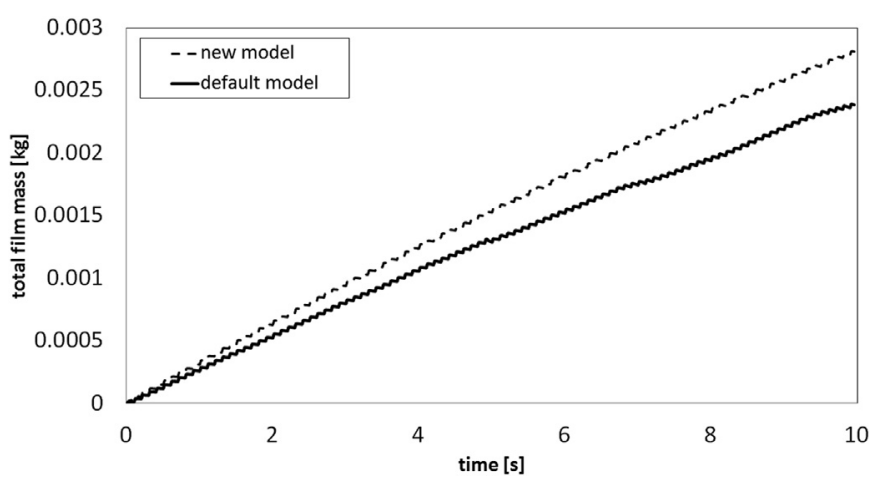

Fig. 12. Comparison of total film mass.

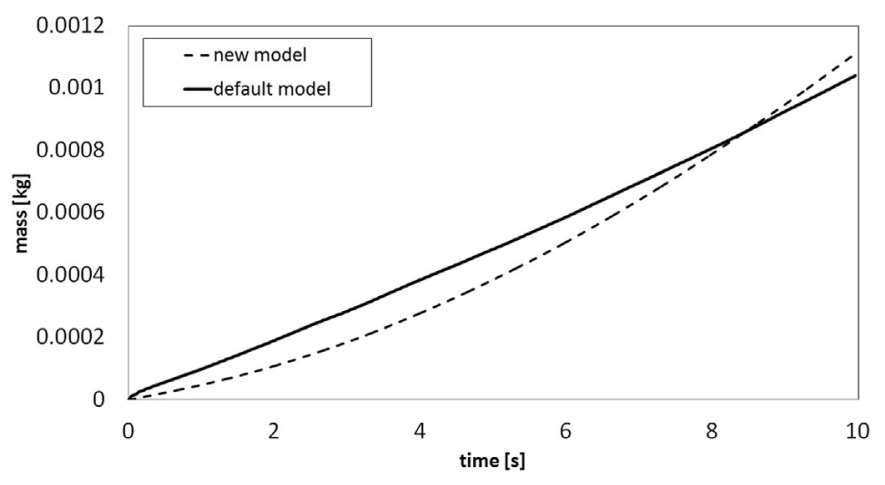

Fig. 13. Comparison of evaporated film mass.

Fig. 10 shows the wall film evolution with newly developed surface tension model incorporated into the existing numerical framework. Similar remarks regarding the relative increase in surface covered with a film are also equally applicable here. However, it can be noticed that the surface tension force has important impact on the formation of the film front as well as on the absolute amount of surface covered with film. Area covered by the film at the given time is greater than in the default model, which means that default model has more intense evaporation rate. Although area occupied by the film is greater in the simulation with the surface tension model, thickness of the film is evenly distributed and evaporation rate is smaller. On the other hand, in the default model the film is very thin, except for the clumps in the boundary regions that enable fast evaporation in spite of the fact that the film surface is smaller. The described line of reasoning is proved by Figs. 11-13, which show comparison of the default and the new model in terms of total film mass, total film area and evaporated film mass. It can be seen that, although the area covered by the film in the new model is greater, the total film mass is also greater. That suggests that the difference in the film mass between the two models is due to the evaporation effects depicted in Fig. 13. However, after $8 \mathrm{~s}$ the effects of greater film area in the new model prevail over effects of thin film in the old model.

The Fig. 14 shows changes in the mole fractions of the thermolysis products along the channel height on the domain exit for both simulated cases. Considering only the experimental results, there is no noticeable trend. The shape and size of the sampling port in the experiment (ellipse with dimensions of major and minor axis of 10 and $8 \mathrm{~mm}$ ) have introduced uncertainty in the measured results because of the relatively large area that it encompassed. The higher concentrations of ammonia compared to the concentrations of isocyanic acid in each case indicate that the hydrolysis of isocyanic acid occurred according to the Equation (3). Higher evaporation rate in the default model suggests that the production of HNCO will be higher, which is exactly what can be seen on the left part of Fig. 14. The new model shows reasonable agreement with experimental data and improvement of existing model. In the case of ammonia concentrations depicted in the right part of Fig. 14, influence of the surface tension model can only be noticed on the low channel heights. It seems that the change in evaporation trend after $8 \mathrm{~s}$ depicted in Fig. 13 influences concentration of ammonia on the $30 \mathrm{~mm}$ height.

\section{Conclusion}

Numerical modeling of the physical phenomena taking place during the urea water based selective catalytic reduction provides a valuable tool that can be used for the investigation and better understanding of the chemical kinetics and pollutant reduction from diesel engine propelled vehicles. A numerical model for the prediction of the generation of ammonia from UWS precursor that takes into account spray/wall interaction and wall film formation was tested and compared with experimental measurements. Furthermore, the existing framework was extended by incorporation of the surface tension model, which was first validated with analytical expression of droplet spreading, and then compared to the experimental data and with the default model. The model is detailed enough to describe properly all the relevant physical and chemical processes, yet simple enough to run on the real industrial meshes needed for detailed CFD simulations of SCR devices.

The obtained results showed satisfactory agreement with the experimental data. The new model of surface tension proved better in describing the physical reality. The improved model of liquid wall film behavior developed here may prove as a valuable contribution in continuous process where constant improvement of accuracy of the physical model used in CFD is conditio sine qua non in order to comply with the ever increasing requirements of the industry (Mikulčić et al., 2015). By using CFD tools it is possible to produce
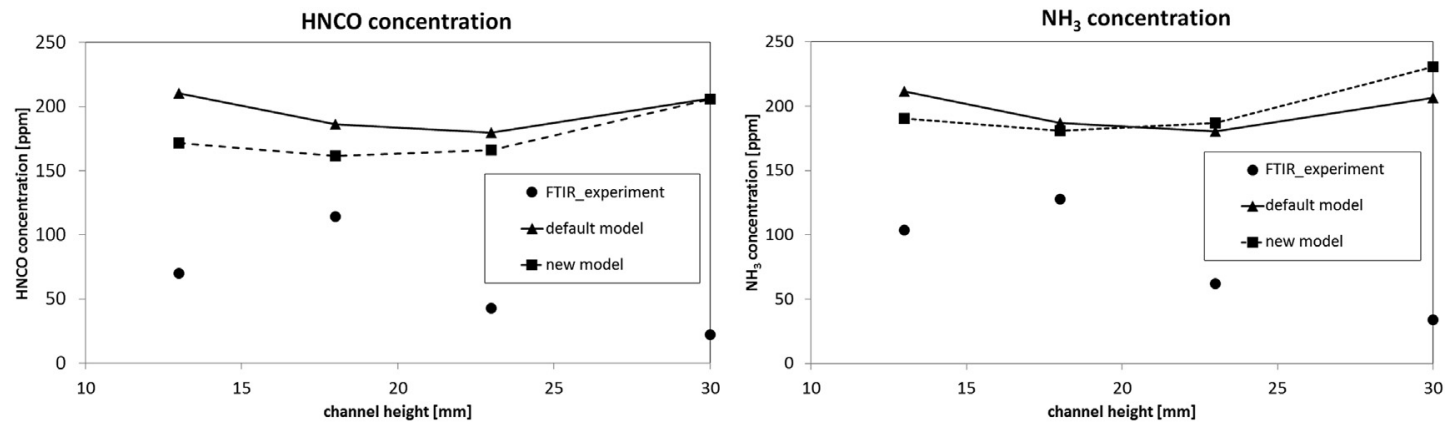

Fig. 14. Urea thermolysis products - comparison with experimental data. 
more efficient, environmentally friendlier SCR technology for improved gas aftertreatment.

$\begin{array}{ll}\text { Abbreviations } \\ \text { CFD } & \text { Computational Fluid Dynamics } \\ \text { EC } & \text { European Commission } \\ \text { FTIR } & \text { Fourier transform infrared spectroscopy } \\ \text { LEVs } & \text { low emission vehicles } \\ \text { PSD } & \text { particle size distribution } \\ \text { SCR } & \text { selective catalytic reduction } \\ \text { UWS } & \text { urea water solution }\end{array}$

\section{References}

Abramzon, B., Sirignano, W.A., 1989. Droplet vaporization model for spray combustion calculations. Int. J. Heat Mass Transf. 32 (9), 1605-1618. http://dx.doi. org/10.1016/0017-9310(89)90043-4.

Bai, C., 1996. Modelling of Spray Impingement Processes. Ph.D. thesis. Imperial College, University of London.

Birkhold, F., Meingast, U., Wassermann, P., Deutschmann, O., 2006. Analysis of the Injection of Urea-water-solution for Automotive SCR DeNO $x^{-}$-systems: Modeling of Two-phase Flow and Spray/Wall-Interaction. SAE 2006-01-0643 (http://dx. doi.org/10.4271/2006-01-0643.

Birkhold, F., Meingast, U., Wassermann, P., Deutschmann, O., 2007. Modeling and simulation of the injection of urea-water-solution for automotive SCR DeNO $x^{-}$ systems. Appl. Catal. B Environ. 70, 119-127. http://dx.doi.org/10.1016/j.apcatb. 2005.12.035.

Diez, J.A., Gratton, R., Thomas, L.P., Marino, B., 1994. Laplace pressure driven drop spreading. Phys. Fluids 6 (1), 24-33. http://dx.doi.org/10.1063/1.868072.

Dukowicz, J.K., 1979. Quasi-steady Droplet Phase Change in the Presence of Convection. Informal Report. Los Alamos Scientific Laboratory. LA-7997-MS. http:// dx.doi.org/10.2172/6012968.

European Union, 2007. Regulation (EC) No 715/2007.

Fang, H.L., DaCosta, H.F.M., 2003. Urea thermolysis and $\mathrm{NO}_{x}$ reduction with and without SCR catalysts. Appl. Catal. B: Environ. 46 (1), 17-34. http://dx.doi.org/ 10.1016/S0926-3373(03)00177-2.

FIRE v2013.2 Manual, 2013. Graz, Austria.

Francois, M.M., Cummins, S.J., Dendy, E.D., Kothe, D.B., Sicilian, J.M., Williams, M.W., 2006. A balanced-force algorithm for continuous and sharp interfacial surface tension models within a volume tracking framework. J. Comp. Phys. 213 (1), 141-173. http://dx.doi.org/10.1016/j.jcp.2005.08.004.

Friedrich, M.A., Lan, H., Wegener, J.L., Drallmeier, J.A., Armaly, B.F., 2008. A separation criterion with experimental validation for shear-driven films in separated flows. J. Fluids Eng. 130, 051301. http://dx.doi.org/10.1115/1.2907405.

Gapin, A., Demoulin, F., Dumouchel, C., Pajot, K., Patte-Rouland, B., Réveillon, J., 2010. Development of an initial drop-size distribution model and introduction in a CFD code to predict spray evolution. In: 7th International Conference on Multiphase Flow ICMF 2010, Tampa, Florida.

Hanjalić, K., Popovac, M., Hadžiabdić, M., 2004. A robust near-wall elliptic-relaxation eddy-viscosity turbulence model for CFD. Int. J. Heat Fluid Flow 25 (6), 1047-1051. http://dx.doi.org/10.1016/j.ijheatfluidflow.2004.07.005.

Horvat, K., 2007. Computational Modelling of Spray Impingement Accounting for the Wall Film Formation. Forschungsberichte Stromungslehre Und Aerodynamik, Shaker Verlag, Gemany.

Kim, J.Y., Ryu, S.H., Ha, J.S., 2004. Numerical prediction on the characteristics of spray-induced mixing and thermal decomposition of urea solution in SCR system. In: Proc. 2004 Fall Technical Conference of the ASME Internal Combustion Engine Division, Long Beach, California, USA, pp. 165-170. http:// dx.doi.org/10.1115/ICEF2004-0889.

Klemeš, J.J., Varbanov, P.S., Huisingh, D., 2012. Recent cleaner production advances in process monitoring and optimisation. J. Clean. Prod. 34, 1-8. http://dx.doi. org/10.1016/j.jclepro.2012.04.026.

Klemeš, J.J., Varbanov, P.S., Pierucci, S., Huisingh, D., 2010. Minimising emissions and energy wastage by improved industrial processes and integration of renewable energy. J. Clean. Prod. 18 (9), 843-847. http://dx.doi.org/10.1016/j.jclepro.2010. 02.028 .

Kontin, S., Höfler, A., Koch, R., Bauer, H.J., 2010. Heat and mass transfer accompanied by crystallisation of single particles containing urea-water-solution. In: ILASS Europe 2010, 23rd Annual Conference on Liquid Atomization and Spray Systems, Brno, Czech Republic.

Kröcher, O., Elsener, M., Jacob, E., 2008. New reducing agents for the low $\mathrm{NO}_{x}$ SCR technology. In: Proceedings of the 5th International Exhaust Gas and Particulate Emissions Forum, Ludwigsburg (Germany), pp. 98-119.

Kuhnke, D., 2004. Spray/Wall-Interaction Modelling by Dimensionless Data Analysis. Shaker Verlag GmbH.

Liu, W., Lund, H., Vad Mathiesen, B., 2013. Modelling the transport system in China and evaluating the current strategies towards the sustainable transport development. Energy Policy 58, 347-357. http://dx.doi.org/10.1016/j.enpol 2013.03.032.

Mikulčić, H., Vujanović, M., Duić, N., 2015. Improving the sustainability of cement production by using numerical simulation of limestone thermal degradation and pulverized coal combustion in a cement calciner. J. Clean. Prod. 88, 262-271. http://dx.doi.org/10.1016/j.jclepro.2014.04.011.

Mikulčić, H., von Berg, E., Vujanović, M., Priesching, P., Perković, L., Tatschl, R. Duić, N., 2012a. Numerical modelling of calcination reaction mechanism for cement production. Chem. Eng. Sci. 69 (1), 607-615. http://dx.doi.org/10.1016/ j.ces.2011.11.024.

Mikulčić, H., von Berg, E., Vujanović, M., Priesching, P., Tatschl, R., Duić, N., 2013. Numerical analysis of cement calciner fuel efficiency and pollutant emissions. Clean. Techn. Environ. Policy. 15 (3), 489-499. http://dx.doi.org/10.1007/ s10098-013-0607-5.

Mikulčić, H., Vujanović, M., Fidaros, D.K., Priesching, P., Minić, I., Tatschl, R., Duić, N., Stefanovic, G., 2012b. The application of CFD modelling to support the reduction of $\mathrm{CO}_{2}$ emissions in cement industry. Energy 45, 464-473. http://dx.doi.org/ 10.1016/j.energy.2012.04.030.

Musa, S.N.A., Saito, M., Furuhata, T., Arai, M., 2006. Evaporation characteristics of a single aqueous urea solution droplet. In: International Conference on Liquid Atomization and Spray Systems (ICLASS).

Nguyen, T.D.B., Lim, Y., Eom, W.H., Kim, S.J., Yoo, K.S., 2010. Experiment and CFD simulation of hybrid SNCR-SCR using urea solution in a pilot-scale reactor Comput. Chem. Eng. 34 (10), 1580-1589. http://dx.doi.org/10.1016/j. compchemeng.2009.12.012.

O'Brien, S.B.G., Schwartz, L.W., 2006. Thin Film Flows: Theory and Modeling, Encyclopedia of Surface and Colloid Science, second ed. Marcel Dekker, Inc, pp. 6304-6317.

Schwartz, L.W., Weidner, D.E., 1995. Modeling of coating flows on curved surfaces. J. Eng. Math. 29, 91-103. http://dx.doi.org/10.1007/BF00046385.

van Helden, R., Verbeek, R., Willems, F., van der Welle, R., 2004. Optimization of Urea SCR deNO ${ }_{x}$ Systems for HD Diesel Engines. SAE 2004-01-0154. http://dx. doi.org/10.4271/2004-01-0154.

Wang, T.J., Baek, S.W., Lee, S.Y., Kang, D.H., Yeo, G.K., 2009. Experimental investigation on evaporation of urea-water-solution droplet for SCR applications. AIChE J. 55 (12), 3267-3276. http://dx.doi.org/10.1002/aic.11939.

Yim, S.D., Kim, S.J., Baik, J.H., Nam, I., Mok, Y.S., Lee, J.H., Cho, B.K., Oh, S.H., 2004 Decomposition of urea into $\mathrm{NH}_{3}$ for the SCR Process. Ind. Eng. Chem. Res. 43 (16), 4856-4863. http://dx.doi.org/10.1021/ie034052j. 